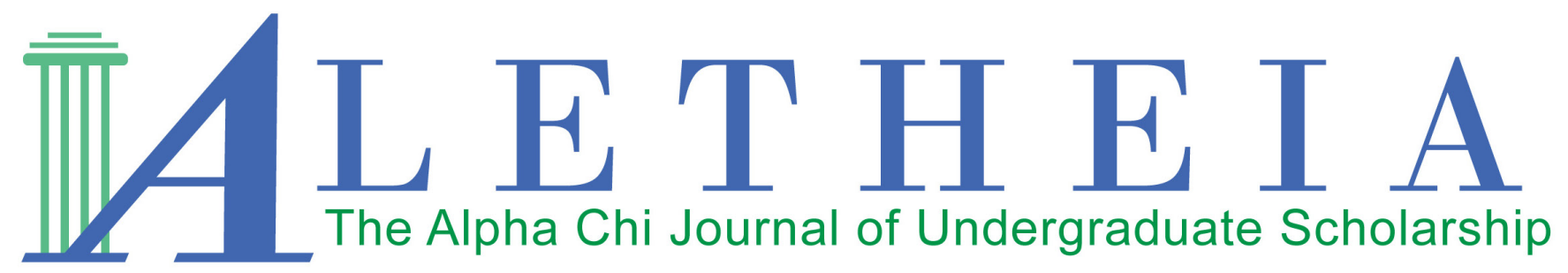

Volume 6 | Issue 2 | 2021

\title{
How Jules Verne Connects Chemistry to \\ Our Anthropocentric World in The Mysterious Island
}

\author{
John Pruden \\ Lyon College \\ Arkansas Iota Chapter
}

Vol. 6(2), 2021

Title: How Jules Verne Connects Chemistry to Our Anthropocentric World in The Mysterious Island DOI: $10.21081 / \mathrm{ax} 0309$

ISSN: $2381-800 \mathrm{X}$

Keywords: anthropocene, chemistry, technology, post-colonial, science fiction, French This work is licensed under a Creative Commons Attribution 4.0 International License.

Author contact information is available from tlindblom@alphachihonor.org or kvosevich@alphachihonor.org

\section{Aletheia-The Alpha Chi Journal of Undergraduate Scholarship}

- This publication is an online, peer-reviewed, interdisciplinary undergraduate journal, whose mission is to promote high quality research and scholarship among undergraduates by showcasing exemplary work.

- Submissions can be in any basic or applied field of study, including the physical and life sciences, the social sciences, the humanities, education, engineering, and the arts.

- Publication in Aletheia will recognize students who excel academically and foster mentor/mentee relationships between faculty and students.

- In keeping with the strong tradition of student involvement in all levels of Alpha Chi, the journal will also provide a forum for students to become actively involved in the writing, peer review, and publication process.

- More information can be found at www.alphachihonor.org/aletheia. Questions to the editors may be directed to tlindblom@alphachihonor.org or kvosevich@alphachihonor.org.

Alpha Chi National College Honor Society invites to membership juniors, seniors, and graduate students from all disciplines in the top ten percent of their classes. Active on nearly 300 campuses nationwide, chapters induct approximately 10,000 students annually. Since the Society's founding in 1922, Alpha Chi members have dedicated themselves to "making scholarship effective for good." Alpha Chi is a member in good standing of the Association of College Honor Societies, the only national accrediting body for collegiate honor societies. A college seeking a chapter must grant baccalaureate degrees, be regionally accredited, and be a not for profit institution. 


\author{
How Jules Verne Connects Chemistry to \\ Our Anthropocentric World in The Mysterious Island \\ John Pruden \\ Lyon College \\ Arkansas Iota Chapter
}

\begin{abstract}
Both French and American consciousness regard Jules Verne as a popular writer of "hard" science fiction, being nearly prophetic in his depiction of scientific advancements. However, Verne himself has described this seeming precognition as "pure and simple coincidence" due to his accurate depictions of simple scientific processes. Verne does not depict science as positive or negative, but simply uses science as a hook on which to hang adventure. In The Mysterious Island, a story about a group of castaways stranded on an island, Verne depicts the development of technology and the castaways' subsequent colonization of the island. This paper argues that The Mysterious Island is not a positive or negative commentary on the impacts of colonialism (a matter Verne is known for being publicly silent about), but rather on the unintended consequences of an increasingly anthropocentric world. Just as Verne uses science as a "hook" for an adventure story, he uses the consequences of colonialism to show the unique difficulties of an anthropocentric society and its unintended consequences.
\end{abstract}

Keywords: anthropocene, chemistry, technology, post-colonial, science fiction, French 
In popular culture, many consider Jules Verne to be the father of "hard" science fiction, being nearly prophetic in his depictions of scientific advancements. However, many academics dispute this idea, citing authors like H.G. Wells and Mary Shelley as the true first authors of science fiction (Derbyshire 81). Even Jules Verne himself referred to his "prophecies" as "pure and simple coincidence, undoubtedly due to the fact that, even when I invent a scientific phenomenon, I always try to make things as real and simple as possible" (Harpold 11). Critics of a prophetic interpretation of Verne's works claim that Verne did not introduce new science in his novels, but instead used a basic understanding of the science of his time as a "hook" upon which to hang stories of grand adventures. Simply put, the subjects of Verne's stories were humans, not science (Angenot 34). Despite this academic consensus, Verne still has a place in American and French consciousness as a prophetic scientific writer.

In The Mysterious Island, Verne depicts science as the cause of both positive and negative impacts on the novel's isolated society. The French and British empires, arguably the most impactful human forces of his time, allow Verne to use the idea of science as a double-edged sword to underscore the same duality inherent in colonialism. This paper argues that Verne was commenting not on the impacts of French colonialism specifically, but rather on the unintended consequences of an increasingly anthropocentric world. Just as Verne uses science as a hook to hang a story of adventure, so he uses the consequences of colonialism to show the unique difficulties of an anthropocentric society and its unintended consequences.

To advance this argument, this author will show how technology influences the plot of Verne's novel by using The Mysterious Island as a case study, placing its technology in literary and historical context, and then examining the influences of technology on its colonial setting. This setting allows Verne to examine the impact of humans on their environment, colonization being the largest human enterprise of Verne's time.

\section{The Chemistry of The Mysterious Island in Context}

From the smallest refinement in a chemical reaction to the discovery of nuclear fission, every scientific discovery has had some impact on our world. Different people perceive these impacts differently, with many ba- sic dystopian or utopian depictions of a future world being dependent on how one's society views and harnesses scientific power. Verne himself depicts a dystopian future in Paris in the 20th Century, a story following a 16-year-old "who graduates, with a devotion to literature and the classics, but finds they have been forgotten in a futuristic world where only technological writing is favored" (Taves). In a world with rapidly increasing scientific discoveries, Verne's work forces the reader to contend with the responsibilities of scientific power. The Mysterious Island-which Verne called a "roman chimique" or a "chemical romance" (Jensen 213) - is a perfect environment to show this influence. Verne places the castaways' scientific discoveries in the society of the island, the castaways making these discoveries for the first time on the island. Due to the castaways' limited resources, the development of technology on the island parallels our own global development of technology. The island and the castaways thus serve as an earth in-miniature, showing the duality of these "novel" discoveries and their resulting influence on the island while highlighting the ever-changing complexities of our own world.

By analyzing the technological developments from the novel-pottery, simple metal tools, sulfuric acid, nitroglycerin, pyroxyle, batteries, and the telegraph - one can clearly see how these developments show how science can accelerate a society through culture, colonization, conflict, and communication.

\section{The Creation of Pottery}

The first technological development of the island is pottery. Cyrus Smith having "discovered pyrites, clay, limestone, and coal deposits on the island...the castaways manufacture bricks from fired clay and make more from stone and lime, the latter being produced by thermally decomposing limestone and slaking the resulting quicklime with water" (Jensen 209). Verne describes this process accurately: the castaways discover limestone, create quicklime, then build a pottery kiln. An authoritative $19^{\text {th }}$-century textbook describes "the great source of this base is the various chalk and limestone deposits found in the geological formations of every country.... Ordinary lime may be prepared from most of these....All that is required is to expel the carbonic acid; and heat is the best agent for effecting this. Kilns of various constructions are employed" (Muspratt). 
Despite scientists discovering the creation of pottery and quicklime centuries ago, "pottery has had a central role in human society for many millennia, but the reasons for the emergence and spread of this technology are poorly understood [by anthropologists]" (Lucquin 3991). Humans having invented pottery to accommodate new cooking and food-storage techniques was the working hypothesis, a hypothesis which readers see in action in The Mysterious Island. The castaways first create pottery "to cook their food" (Verne 55). Upon discovering a new source of food - agouti and capybara-they use their new pottery to cook it. However, they also use the clay with metal to create "other instruments...blades for planes, axes, hatchets...saws chisels...Spades, pickaxes, hammers, nails, etc" (Verne 56). Verne's list consists of tools that can double as weapons, despite the castaways primarily using them to harvest raw materials.

Additionally, the simple technology allows the castaways to harvest food more efficiently, a simple example being oysters. Upon discovering an oyster bed, Gideon supposes that the castaways "shall have an inexhaustible supply," and Neb and Pencroff harvest "a quantity of the mollusks...in a sort of net" (Verne 50). Later, after developing simple tools, Neb and Pencroff are able to "drag with them [to the oyster bed] a sort of rough cart... [bringing] back some thousands of oysters" (Verne 72). This scene shows that even simple technology has complex impacts on society. Using these basic tools, the castaways are able to increase their harvesting methods exponentially, create rudimentary weapons, and potentially wipe out an entire species. The impacts of this development are clear; after a few years, Cyrus notes that "if [their hunting of animals] continued, the jaguar race would soon be extinct" (Verne 152).

There is, however, emerging evidence that cultural factors - rather than purely practical ones-influenced the development of pottery. An example of this cultural development can be found in the remains of the prehistoric Jomon of Japan. Wanting to test the hypothesis that humans invented pottery to support new cooking techniques, researchers used "chemical analysis... of pottery across an exceptionally long 9,000 year sequence from the Jomon site of Torihama," showing that "molecular and isotopic analyses of lipids from vessels provides clear evidence that pottery across this sequence was predominantly used for cooking marine and freshwater resources....Conversely, there is little indication that ruminant animals or plants were pro- cessed in pottery" (Lucquin 3991). In short, this study shows that even after creating novel foods and cooking techniques, Japanese people still primarily used pottery for fish-based cooking. This link was "established in the Late Paleolithic and lasted well into the Holocene," demonstrating that "cooking aquatic products in pottery represents an enduring social aspect of East Asian hunters" (Lucquin 3991). Despite this study taking place centuries after Verne's death and being technologically beyond anything he could have predicted, one can interpret the castaways' later use of pottery through this lens. The castaways use pottery throughout the novel to cook their food, but do not develop novel cooking utensils to accommodate new sources of food; their traditional "repas" (an untranslated French word in the translated English edition commonly meaning a traditional meal) stays the same throughout the novel.

Despite their conflicts, these interpretations of this technology do not create a paradox that needs resolving; this paradox is, in part, why Verne introduced the idea of pottery. Verne did not base his depiction of the creation and use of pottery on novel research, but rather showed how humans during his time actually used it. In doing this, Verne cannot incorrectly "predict" the future; he is simply describing the present. Verne is not so much predicting how pottery will change the castaways' lives as he is using the technology of pottery to examine the society of the island, and therefore society as a whole.

\section{Chemical Synthesis - Sulfuric Acid, Nitroglycerine, and Pyroxyle}

The castaways of The Mysterious Island use numerous chemical reactions, notably the synthesis of sulfuric acid, nitroglycerine, and pyroxyle, while attempting to create shelter and a way to defend themselves. Sulfuric acid serves as a precursor material for both nitroglycerin and pyroxle; the castaways synthesize nitroglycerin to create shelter in a granite formation (Verne 61), and pyroxle to "reserve [their limited gunpowder] for the future...then prepare for the unknown future by husbanding their ammunition and by substituting for it some easily renewable substance" (Verne 109).

In order to synthesize both materials, Cyrus must make the precursor material, sulfuric acid. Upon finding a "vein of coal... schistose pyrites...composed principally of coal, flint, alumina, and sulphuret of iron," Cyrus begins, separating "the sulphuret of iron... [to] transform 
it into sulphate as rapidly as possible." Then, reducing the pyrites "by fire, the result of the operation, consisting of sulfate of iron, sulfate of alumina, flint, remains of coal, and cinders, was placed in a basinful of water. [The castaways] stirred this mixture, let it settle, then decanted it, and obtained a clear liquid containing solution sulfate of iron and sulfate of alumina" (Verne 61). Having obtained sulfate of iron and alumina, Cyrus then synthesizes "sulphuric acid...[having] only one operation to make, to calcine the sulphate of iron crystals in a closed vase, so that the sulphuric acid should distill in vapor, which vapor, by condensation, would produce the acid. The crystals were placed in pots, and the heat from the furnace would distill the sulphuric acid" (Verne 62). Chemists documented this process well during Verne's time, creating what scientists called "Nordhausen sulfuric acid," made by "the distillation of a dried ferrous sulfate in earthen retorts" which "[fumed] strongly in contact with air" and "heat [decomposing] it into sulfuric acid" (Youmans 239-240).

After creating sulfuric acid, Cyrus sets out to create nitroglycerine, doing so by mixing nitric acid and glycerin. Nitric acid, also known as azotic acid, "until the early 1900s was produced by heating saltpeter $\left(\mathrm{KNO}_{3}\right)$ with sulfuric acid" (House 271), which is the exact method Cyrus employs, using "saltpeter, attacked by sulfuric acid" to yield "azotic or nitric acid" (Verne 62). Cyrus then mixes the nitric acid with glycerine, obtaining "several pints of an oily, yellow liquid" (Verne 62). Ascanio Sobrero discovered nitroglycerin in 1847 in this exact way "by adding glycerol to a mixture of concentrated nitric and sulfuric acids" ("Nitroglycerin"). In section two of the novel, Cyrus decides to use nitric acid to create "pyroxle, that is to say guncotton." To do this, "the cotton must be immersed in the fuming azotic acid for a quarter of an hour, then washed in cold water and dried" (Verne 109).

The potential uses of nitroglycerine quickly become a source of conflict between Pencroff and Cyrus. Pencroff asks Cyrus if he thinks "that by means of that charming liquid you have made, one could blow up the whole of our island," to which Cyrus responds, "without any doubt," thereby proving the proclaimed "terrible" nature of the chemical. Despite this, Pencroff immediately responds with the question: "Then could you not use this nitroglycerine for loading firearms?" (Verne 64). Though Cyrus created the nitroglycerine simply to find shelter, Pencroff quickly encourages him to create guncotton, which eventually leads the castaways into conflict with other individuals on the island. The creation of guncotton demonstrates Cyrus's acceptance of the necessity of self-defense. In the same way that pottery illustrated civilization in their colony, the development of weapons shows the conflict of an anthropocentric society. While some cultures may seek to conserve resources and act sustainably, others may seek to eliminate sources of conflict as easily as possible. Furthermore, the perspectives of certain cultures can shift as their needs adjust, in the same way that Cyrus eventually acquiesces to Pencroff's request.

By showing the duality of Cyrus's and Pencroff's responses, Verne emphasizes the duality of chemistry in this micro-society as well as the duality of the effects of humans in our own society. Describing the nitroglycerine as "this terrible product," Verne simultaneously welcomes and rejects the impacts of science; therefore, he maintains that science exists naturally in a sphere of contradictory applications, and that science should not inherently be praised or rejected, but rather treated as a tool which humanity uses to impose its own will on the world (Verne 62).

\section{The Battery and The Telegraph}

The last invention to explore is the simple battery and telegraph system, created to "put the corral [of herded animals] in instantaneous communication with [their shelter] Granite House" (Verne 146). To make the telegraph, Cyrus first needs to find a source of energy. Verne's settles on "an unusual acid/alkaline battery, invented in 1820 by the French physicist and electrochemist Antoine-Cesar Becquerel" (Jensen 211). Cyrus sets up this acid/alkaline battery using two electrodes of the same metal, with one placed in an acid solution and the other placed in a basic/alkaline solution - in this case, $\mathrm{H}\left(\mathrm{NO}_{3}\right)$ and $\mathrm{K}_{2}\left(\mathrm{CO}_{3}\right)$, respectively. Cyrus connects these solutions with a porous transfer mechanism, such as a salt-bridge or a porous plug. While this battery works in concept, it was unusual even for Verne's time, relying on the electrochemical idea of harvesting energy from a difference in solution rather than a difference in metal. Additionally, the use of zinc rather than Becquerel's original platinum becomes "the source of a serious defect in his scheme... all attempts to use zinc for the electrode in the nitric acid half-cell led to its rapid destruction" (Jensen 212). However, given Cyrus's limited resources, he 
may have been "unable to construct batteries based on the chemical difference between two metal electrodes, since that would lead to the net consumption of their strictly limited supply of zinc" (Jensen 212).

The telegraph serves to connect the castaways with each other and eventually to Captain Nemo by following the wire Nemo used on their isolated telegraph grid (Verne 217). The creation of the telegraph therefore serves as the beginning of the end of the novel; once the castaways have created a means of communicating, all that's left is to explore further and eventually leave the island for a new land. By choosing the telegraph for the book's final invention, Verne comments on society after the book's events. In this era, an electric futureand especially a global electric future-was not taken for granted. The idea that electricity would have global implications affirms the future importance of electricity, but rather than telling a story of "an electric world" with electrical developments and instant communication, Verne instead shows how the development of the telegraph inevitably leads to departure from the island and prevents the island from exploding. The telegraph itself did not save the castaways; they saved themselves by using the telegraph to explore their own world.

\section{The Island as an Analog to Large-Scale Human Influence}

While Verne may not have intended an ecological reading of his works, his exploration of the impact of colonization lends itself to these readings. Just as colonization was the most impactful large-scale human development of his time, so environmentalism is in our modern society. Furthermore, there may be new large-scale crises that arise in the future for which Verne's novels are applicable. Rather than commenting specifically on one force of humankind, Verne chose to center his works on the expansion of an anthropocentric society and its many consequences. As established in the preceding section, Verne shows the application of these discoveries as having positive and negative impacts on their island society, with these impacts becoming increasingly difficult to track. In doing so, Verne was not advocating for or rallying against specific scientific ideas, but rather placing them in the context of a developing society.

Many have argued that Verne's works are "anti-capitalistic, anti-imperialistic, and anti-establishment" (Winandy 97), while others argue that Verne was pro-colonization and slavery, one specifically citing the character Jeb - a monkey turned into a servant - as a critique on the idea of a "free" slave (Spangler 79). Some scholars argue that Verne's works prophesied climate change, with The Purchase of the North Pole discussing it as a consequence of the tilt of the earth (Evans 35). Others argue that Verne never intended for his works to be read in an ecological sense, as the French words "environ" and "environnement" were not being used in an environmentalist sense during Verne's time (Harpold 22). These contrasting interpretations of Verne's works have a common idea: they critique the social structures in Verne's works and show the path of an increasingly anthropocentric society as having contrasting consequences.

In the same way that Verne used science as a "hook" to tell stories of adventure, Verne used colonialism and exploration as the setting to tell stories of humans influencing their environment. The largest social structure of Verne's time was the colonial French enterprise (the second French colonial empire beginning with the conquest of Algeria, and eventually becoming the second largest colonial enterprise of the 20th century), second only to the British Empire (Taagepera 493, 502). It therefore makes sense that Verne would use colonization as a background to tell a story of human influence. Although colonialism was a major human enterprise, Verne's contemporaries did not explicitly perceive him as anti-colonialist. This was not unusual for this era: Victor Hugo was another contemporary of Verne and prominent author who was unclear about his stance on colonization. Despite writing in Les Miserables that "Algeria [is] too harshly conquered, and, as in the case of India by the English, with more barbarism than civilization," Hugo never condemned the conquest of Algeria publicly (Hugo 720).

Despite this ambiguity, scholars frequently analyze Verne's works using a post-colonial or anti-capitalistic lens due to a perceived sympathy for colonized peoples (Ousselin 88; Winnande 97). Thus, there is a paradox to solve: "How can we reconcile these sympathetic markings towards colonized peoples [in Verne's works] with the eloquent silence of Verne relating to the ensemble of the colonial French enterprise?" (Ousselin 90). Some authors choose to solve the paradox by exploring the characters. Ousselin argues that Nemo serves as a sort of "demiurgical" character between The Mysterious Island, Twenty Thousand Leagues Under the Seas, and The 
Children of Captain Grant. By providing a character as a bridge between these stories, which in themselves tell the story of colonialism from three different angles (The Mysterious Island being a tale about the colonizers, Twenty-Thousand Leagues Under the Seas being a tale about the struggle against colonialism, and The Children of Captain Grant being a tale about the crossing of colonized lands), Ousselin argues that Nemo's relationship with the main character of "the man of science" in each story shows Verne's relationship with colonization (Ousselin 89). Although a character sharing Verne's perspective on colonialism sheds light on Verne's own beliefs, this alone cannot fully answer the question. To resolve the paradox, it is necessary to examine the lens through which Verne views science in The Mysterious Island. Verne did not write The Mysterious Island as a condemnation of science, nor as a celebration of it, but rather to show how scientific ideas can grow in complexity and influence society in unpredictable ways. In this same way, The Mysterious Island is not a condemnation or celebration of colonization, but rather an examination of how the growing influence of humankind on the earth can create unexpected and complex impacts and thus create conflicting interpretations of these impacts.

In order to make these impacts clearer, Verne's works use a presence d'autrui (literally, "presence of other people") to create a shortened literary "distance" between Verne's characters, arguing that the characters find home in the unknown of the story itself, rather than finding "a privileged place to withdraw...[to] be free from the anguish of evil" (Winandy 104). This presence can be seen in The Mysterious Island when the castaways do not attempt to escape the island immediately, but instead choose to establish a settlement. They only explore the idea of leaving after discovering the presence of other, potentially hostile humans. Instead of withdrawing from the novel's setting, the characters revel in the challenge of reestablishing civilization. Pencroff, after examining the island, is a perfect depiction of this idea, dreaming of "canals facilitating the transport of the riches of the ground, working of quarries and mines; machines for every industrial manufacture; railroads; yes, railroads! Of which a network would certainly one day cover Lincoln Island," rather than escaping the island itself (Verne 68).

Shortening this literary distance, Verne also shows how the events of one story may directly impact the events of another. Captain Nemo and Tom Ayrtonfrom Twenty Thousand Leagues Under the Sea and In
Search of the Castaways, respectively - serve as a direct link between these books and The Mysterious Island, thus connecting their respective settings and characters. In doing this, Verne creates his own consistent universe and shows how the events of the novel change that universe. By the end of The Mysterious Island, Ayrton redeems himself and returns to society, Captain Nemo dies, and the volcano destroys the island. Although the volcano erupting is an inevitable force of nature ("To contend against this disaster would have been folly-nay, madness"), Cyrus explains that the sea coming into contact with the heat of the volcano, through the passage created by their excavation of "Granite House" could create an explosion that would "incur the risk of blowing up a portion of the globe" (Verne 228). Thus, all these influences on the setting and the environment of the novel can directly relate to the actions of the characters. Although Verne writes that "in presence of nature's grand convulsions man is powerless" (Verne 228), Verne is still showing that man can have unintended consequences on even the most awesome forces.

Critics have long compared Verne to authors of contemporary works. John Derbyshire called Jules Verne "The Michael Crichton of the 19th century" (Derbyshire 89), and André Winandy compared his plot devices to those used by Rod Serling in The Twilight Zone. These comparisons are particularly apt, as many of Michael Crichton and Rod Serling's works related societal progress to science, and in doing so raised a mirror to society. Many scholars criticize the contrast between Verne's actions and his writings; critics can resolve this paradox in the same way they generated a consensus on Verne as a scientific writer. In the same way that Verne was not writing or developing pure scientific ideas, he was not arguing for specific political or sociological ideas, but rather using the wide-spread presence of colonialism as a tool - a mirror for society - to show the unintended consequences of an anthropocentric world. 


\section{Works Cited}

Angenot, Marc. "Jules Verne and French Literary Criticism." Science Fiction Studies, vol. 1, no. 1, SF-TH Inc, Spring 1973, pp. 33-37.

Derbyshire, John. "Jules Verne: Father of Science Fiction?" The New Atlantis, Technology \& Society, Spring 2006, pp. 81-90.

Evans, Arthur B. "The 'New' Jules Verne." Science Fiction Studies, vol. 22, part 1, no. 65, SF-TH Inc, March 1995, pp. 35-46.

Harpold, Terry. "Lire Jules Verne dans 1'Anthropocène." Galaxies, no 52, January 2018, pp. 10-23.

House, James E. "Discussions of Chemistry in Jules Verne's The Mysterious Island." The Chemical Educator, vol. 19, Springer-Verlag, 2014, pp. 269-274.

Hugo, Victor. Les Misérables. New York: Random House Publishing Group, 2000.

Jensen, William. "Captain Nemo's Battery: Chemistry and the Science Fiction of Jules Verne." Culture of Chemistry, Springer, 2015, pp. 205-214.

Lucquin, Alexandre. "Ancient lipids document continuity in the use of early hunter-gatherer pottery through 9,000 years of Japanese prehistory." Proceedings of the National Academy of Sciences of the United States of America, vol. 113, no. 15, April 2016, p. 3991-3996.

Muspratt, Sheridan. Chemistry, Theoretical, Practical \& Analytical, as applied to The Arts and Manufactures. Glasgow, Edinburgh, London \& New York, Published by William Mackenzie, c. 1859.

"Nitroglycerin." Encyclopedia Britannica. Chicago. 2015. Available at: https://www.britannica.com/science/nitroglycerin

Ousselin, Edward. "De Nemo à Dakkar. La Représentation Paradoxale du Colonialisme chez Jules Verne." Nineteenth-Century French Studies, vol. 42, no. 1/2, University of Nebraska Press, Fall Winter 20132014, pp. 88-102.

Spangler, May. "L'Utopie Post-Coloniale de "L'Île Mystérieuse." Francofonia, no. 44, Primavera, 2003, pp. 77-98.

Taves, Brian. "Jules Verne's Paris in the Twentieth Century." Science Fiction Studies, vol. 24 part 1, no. 74, SF-TH Inc, March 1997, pp. 33-37. Available at: https://www.depauw.edu/sfs/review_essays/taves $\underline{71 . h t m}$
Verne, Jules. L'île Mystérieuse. CreateSpace. Okitoks Press. Scotts Valley, CA. 2017.

Winandy, André. "The Twilight Zone: Imagination and Reality in Jules Verne's Strange Journeys." Yale French Studies, Translated by Rita Winandy, No. 43, Yale University Press, 1969, pp. 97-110.

Youmans, El.L., New Class Book of Chemistry, D. Appleton \& Co., New York, 1875. 